\title{
Evaluation of in-house PCR for diagnosis of smear-negative pulmonary tuberculosis in Kampala, Uganda
}

Lydia Nakiyingi ${ }^{1,2^{*}+}$, David P Kateete ${ }^{3 \dagger}$, Ponsiano Ocama ${ }^{1,2}$, William Worodria ${ }^{3}$, Joseph B Sempa ${ }^{1}$, Benon B Asiimwe ${ }^{3}$, Fred A Katabazi ${ }^{3}$, Achilles Katamba ${ }^{2}$, Laurence Huang ${ }^{4}$, Moses L Joloba ${ }^{3}$ and Harriet Mayanja-Kizza ${ }^{2}$

\begin{abstract}
Background: Nucleic acid amplification tests (NAATs) have offered hope for rapid diagnosis of tuberculosis (TB). However, their efficiency with smear-negative samples has not been widely studied in low income settings. Here, we evaluated in-house PCR assay for diagnosis of smear-negative TB using Lowenstein-Jensen (LJ) culture as the baseline test. Two hundred and five pulmonary TB (PTB) suspects with smear-negative sputum samples, admitted on a short stay emergency ward at Mulago Hospital in Kampala, Uganda, were enrolled. Two smear-negative sputum samples were obtained from each PTB suspect and processed simultaneously for identification of MTBC using in-house PCR and LJ culture.

Results: Seventy two PTB suspects (35\%, 72/205) were LJ culture positive while 128 (62.4\%, 128/205) were PCR-positive. The sensitivity and specificity of in-house PCR for diagnosis of smear-negative PTB were $75 \%$ (95\% Cl 62.6-85.0) and 35.9\% (95\% Cl 27.2-45.3), respectively. The positive and negative predictive values were 39\% (95\% Cl 30.4-48.2) and 72.4\% (95\% Cl 59.1-83.3), respectively, while the positive and negative likelihood ratios were 1.17 (95\% Cl 0.96-1.42) and $0.70(95 \% \mathrm{Cl} 0.43-1.14)$, respectively. One hundred and seventeen $\mathrm{LJ}$ culturenegative suspects (75 PCR-positive and 42 PCR-negative) were enrolled for follow-up at 2 months. Of the PCR-positive suspects, 45 (60\%, 45/75) were still alive, of whom 29 (64.4\%, 29/45) returned for the follow-up visit; 15 $(20 \%, 15 / 75)$ suspects died while another $15(20 \%, 15 / 75)$ were lost to follow-up. Of the 42 PCR-negative suspects, 22 (52.4\%, 22/42) were still alive, of whom 16 (72.7\%, 16/22) returned for follow-up; 11 (26.2\%, 11/42) died while nine $(21.4 \%, 9 / 42)$ were lost to follow-up. Overall, more PCR-positive suspects were diagnosed with PTB during follow-up visits but the difference was not statistically significant (27.6\%, 8/29 vs. 25\%, 4/16, $p=0.9239)$. Furthermore, mortality was higher for the PCR-negative suspects but the difference was also not statistically significant $(26.2 \%$ vs. $20 \% p=0.7094)$.
\end{abstract}

Conclusion: In-house PCR correlates poorly with $L J$ culture for diagnosis of smear-negative PTB. Therefore, in-house PCR may not be adopted as an alternative to $L J$ culture.

Keywords: Pulmonary tuberculosis, Smear-negative TB, HIV-infected, HIV-TB co-infection, CD4 cell counts, Nucleic acid amplification tests, In-house PCR, Lowenstein-Jensen culture, Sensitivity, Specificity, Resource limited settings

\footnotetext{
* Correspondence: lydikiyingi@yahoo.com

${ }^{\dagger}$ Equal contributors

'Infectious Diseases Institute, Makerere University College of Health Sciences,

Mulago Hospital Complex, Kampala, Uganda

${ }^{2}$ Department of Medicine, School of Medicine, Makerere University College

of Health Sciences, Kampala, Uganda

Full list of author information is available at the end of the article
} 


\section{Background}

The genetically homogeneous subspecies of the Mycobacterium tuberculosis complex (MTBC; M. tuberculosis, M. bovis, $M$. bovis BCG, $M$. africanum, $M$. caprae and $M$. cannetti) cause tuberculosis (TB) [1,2], a global disease that affects one third of the human population $[3,4]$. TB and HIV co-infection affects many in subSaharan Africa [5-7]; Uganda has a high HIV prevalence and is also among the world's 22 high TB-burdened countries with an estimated incidence of 402 cases per 100,000 individuals [3]. Kampala, the capital of Uganda has approx. 2 million inhabitants and accounts for approx. 30\% of the nation's TB burden [4].

Accurate diagnosis is crucial for efficient management of TB patients [3]; however, TB diagnosis remains a challenge particularly in resource limited settings (RLS) where the disease is complicated by HIV co-infection.

Conventional approaches to TB diagnosis in RLS still rely on methods that have major limitations [8-10]. Smear microscopy is the most widely available method but has varying sensitivity (30 to 60\%) particularly in TB-HIV co-infected patients. The chest X-ray, often a supplementary test for diagnosis of smear-negative pulmonary TB (PTB) also has low specificity. Solid cultures are used as confirmatory tests but are expensive, lengthy (up to 8 weeks) and not widely available in RLS [11].

The World Health Organization (WHO) recommends liquid cultures in high TB burdened countries due to the advantage of rapid detection and incremental yield in comparison with solid media [12]. However, liquid culture systems are expensive, prone to contamination and usually support the growth of non-tuberculous mycobacteria (NTM).

Nucleic acid amplification tests (NAATs) are promising new methods for rapid detection of $M$. tuberculosis (MTB) directly in samples or TB culture and are being considered as cost-effective alternatives in RLS $[13,14]$. The latest development was the WHO's endorsement of the GeneXpert (Xpert MTB/Rif) for use in TB endemic countries, declaring the system a major milestone for global TB diagnosis. The high cost notwithstanding [15], some sub-Saharan African countries (e.g. South Africa, Morocco, etc.) have introduced the Xpert MTB/Rif system for routine TB diagnostics. Even then, research on the optimal use of NAATs for TB diagnosis is still wanting in sub-Saharan Africa where there is high burden of HIV/TB co-infection.

An in-house PCR assay for rapid identification of MTBC in smear-positive sputum samples and acid fast bacilli (AFB) positive cultures was previously introduced in this setting [16], but it has never been evaluated for the diagnosis of smear-negative PTB in the same setting. Using LJ culture as the base-line test, this study evaluated in-house PCR for rapid diagnosis of smear-negative
PTB in a low income setting with high burden of TB/ HIV co-infection.

\section{Methods}

\section{Setting, participants and specimen collection}

This study was conducted between September 2007 to February 2008, on a short stay emergency medical ward at Mulago National Referral and Teaching Hospital in Kampala, Uganda. The emergency ward temporarily admits and triages patients before transfer to specialized medical units. Approx. 30 patients per day are admitted, of whom one third have respiratory symptoms. Patients with respiratory symptoms were examined by specialists who identified PTB suspects. PTB suspects were defined as patients with cough for $\geq 2$ weeks with or without any of the following; sputum production, haemoptysis, chest pain, shortness of breath, loss of appetite, weight loss, fatigue, night sweat and fever.

Two sputum samples (one on spot and another early morning) were collected from each PTB suspect and examined by Ziehl-Neelson (ZN) microscopy for identification of AFB [17]. Sputum induction (using 7\% hypertonic saline inhaled by nebulization) was used for patients who were unable to expectorate sputum.

\section{Inclusion/exclusion criteria}

A total 320 PTB suspects were screened; patients with smear-positive sputum samples were excluded but started on TB treatment according to the Uganda National TB guidelines. To be enrolled in the study, a PTB suspect ought to have consecutively produced at least two AFB smear-negative sputum samples upon ZN microscopy. Overall, sputum samples for culture and DNA extraction were obtained from a total of 205 PTB suspects who met the above criteria (i.e. two smear-negative sputum samples); these were recruited as study participants (Figure 1). In addition, demographic and clinical data were obtained from the 205 enrolled participants.

\section{HIV testing}

HIV testing was performed for all the enrolled patients following the algorithm for the ministry of health, Uganda [18]. CD4+ cell counts by BD FACS calibur (Becton and Dickinson, Franklin Lakes, NJ, USA) were performed, as well as chest X-rays.

\section{Sputum processing}

Sputum processing and culture were performed in biosafety level 3 facility at the national TB reference laboratory (NTRL) in Kampala, Uganda. The sputum samples were processed by digestion and decontamination in a biosafety cabinet class II as previously described [16,19]. Briefly, $200 \mu \mathrm{l}$ of digestion buffer $(2.9 \%$ sodium citrate, NAcetyl L-cysteine [NALC] and $6 \% \mathrm{NaOH}$ ) was added to an 


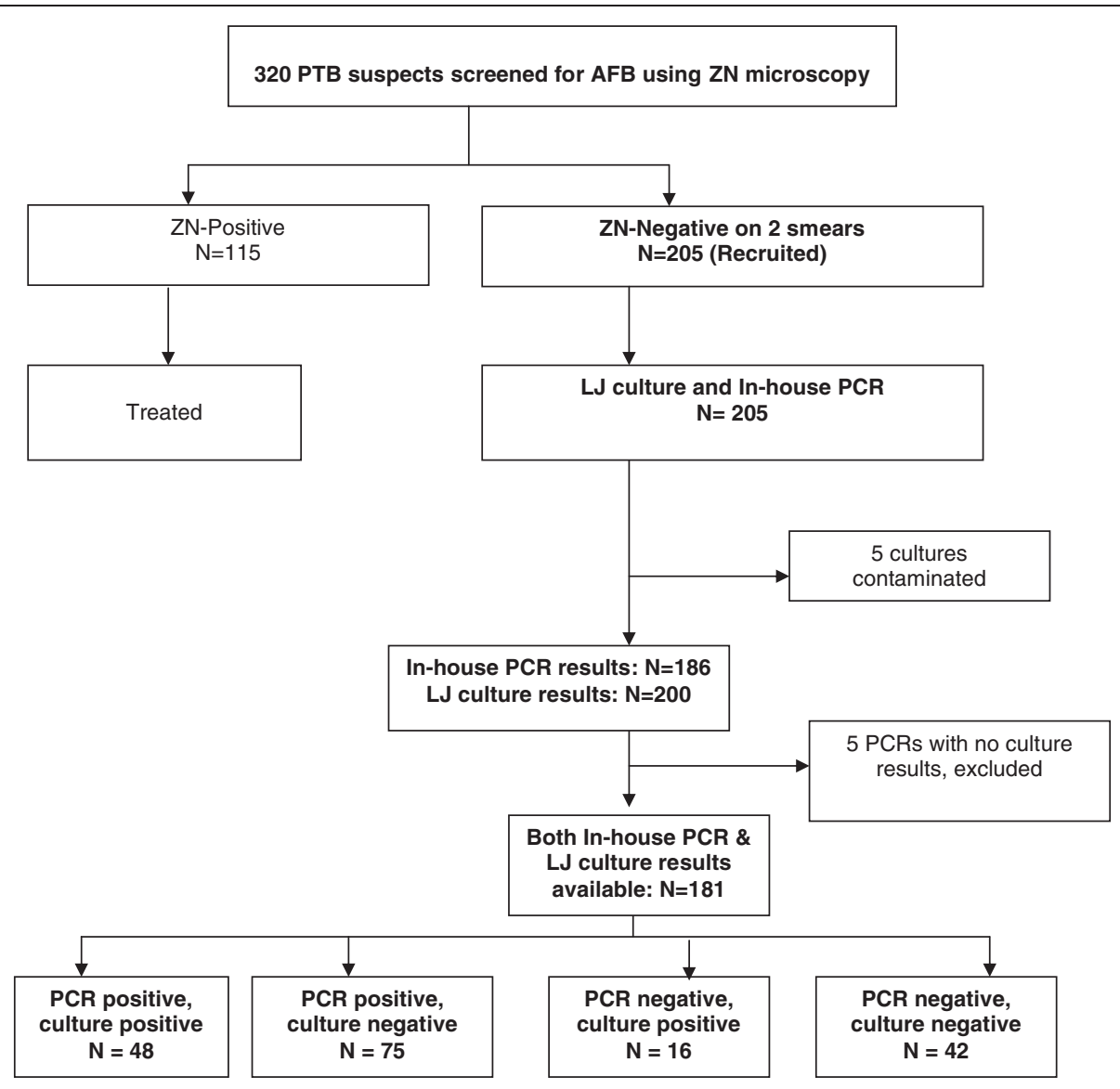

Figure 1 Study flow chart.

equal volume of sputum, vortexed and incubated at room temperature for $15 \mathrm{~min}$. The digested sample was then diluted to $50 \mathrm{ml}$ with phosphate buffer ( $\mathrm{pH}$ 6.8), mixed thoroughly and centrifuged at $4000 \mathrm{~g}$ for $15 \mathrm{~min}$; the sediment was then suspended in $2 \mathrm{ml}$ phosphate buffer.

\section{MTBC cultures}

LJ culture, widely used for TB diagnosis in RLS [20], was used as a baseline test to assess the diagnostic accuracy of in-house PCR. LJ culture was chosen as the gold standard because all the mycobacterial colonies on LJ-positive samples in this setting are predominantly MTBC [21,22]. For cultures, $100 \mu$ leach of the processed sputum (see above) was inoculated into LJ culture bottles and incubated at $37^{\circ} \mathrm{C}$ for up to 3 months. Cultures were considered positive only if mycobacterial colonies appeared within 8 weeks following inoculation. Colonies from culturepositive LJ bottles were confirmed for presence of AFB by ZN microscopy and $16 \mathrm{~s}$ rRNA PCR.

16S rRNA PCR was performed on LJ-positive cultures to confirm mycobacteria (which were presumptively regarded MTBC $[21,22]$ ) and rule out subtle growth from other acid fast bacilli organisms on LJ media (such as
Nocardia, Corynebacteria and Frankia). PCRs were performed on all LJ-positive cultures using the following primers: 5'-ACG GTG GGT ACT AGG TGT GGG TTT C3', forward and 5'-TCT GCG ATT ACT AGC GAC TCC GAC TTC A-3', reverse. The amplification program was as follows: initial denaturation at $94^{\circ} \mathrm{C}$ for $4 \mathrm{~min}$, followed by 31 cycles each consisting of denaturation at $94^{\circ} \mathrm{C}$ for $30 \mathrm{~s}$; annealing at $63^{\circ} \mathrm{C}$ for $30 \mathrm{~s}$ and extension at $72^{\circ} \mathrm{C}$ for $45 \mathrm{~s}$. Then, there was a final extension at $72^{\circ} \mathrm{C}$, for $10 \mathrm{~min}$. Amplicons were analyzed by agarose gel electrophoresis in which a $600 \mathrm{bp}$ fragment was detected in positive samples.

\section{Chromosomal DNA extraction}

DNA extraction and molecular assays were performed at the Molecular Biology Laboratory, Department of Medical Microbiology, Makerere University College of Health Sciences. Approx. $0.5 \mathrm{ml}$ each of the processed sputum samples (see sputum processing) in screw-capped cryovials (Nalgene, Thermo Fisher Scientific, Rochester, USA) were incubated at $80^{\circ} \mathrm{C}$ for $2 \mathrm{~h}$ to heat kill the bacilli. Then, chromosomal DNA was extracted with the Master pure ${ }^{\mathrm{TM}}$ purification kit (Epicentre Biotechnologies, Madison, USA) following the manufacturer's guidelines. 


\section{In-house PCR assays}

The IS6110 insertion sequence, which is unique to the MTBC members $[23,24]$ was the target for the in-house PCR assay. Amplification reactions were performed with primers, P43 (forward, 5'-TCAGCCGCGTCCACGCCG CCA-3'), and P53 (Reverse, 5'-CCGACCGCTCCGACC GACGGT-3') [16], which amplify 521 bp of IS6110. Each reaction contained 20 pmoles of the forward and reverse primer, $1 \mu \mathrm{l}$ of custom PCR-Master mix (10 mM Tris$\mathrm{HC1}$, pH 9.0, $2 \mathrm{mM} \mathrm{MgCl}$, $50 \mathrm{mM} \mathrm{KCl,} 200 \mu \mathrm{M}$ dNTPs and 5\% DMSO), 0.5U Taq polymerase and $2 \mu \mathrm{l}$ of chromosomal DNA template in a reaction volume of $10 \mu \mathrm{l}$.

Amplifications were performed in the PTC-200 Peltier thermocycler (MJ Research, Waltham, USA) under the following conditions: initial denaturation at $94^{\circ} \mathrm{C}$ for $5 \mathrm{~min}$; followed by 34 cycles each consisting of $94^{\circ} \mathrm{C}$, $30 \mathrm{~s} ; 65^{\circ} \mathrm{C}, 30 \mathrm{~s}$; and $72^{\circ} \mathrm{C}, 45 \mathrm{~s}$; and a final extension step at $72^{\circ} \mathrm{C}$ for $10 \mathrm{~min}$. Then, amplicons were electrophoretically analyzed using $1 \%$ agarose gel in TBE (TrisBorate EDTA) buffer stained with ethidium bromide and visualized under ultraviolet (UV) light in a UV transilluminator. Positive control reactions included template DNA purified from MTB strain $\mathrm{H}_{37} \mathrm{Rv}$, while negative controls included reactions with only pure nuclease free water or DNA extracted from M. smegmatis and Escherichia coli. Presence of an approx. $500 \mathrm{bp}$ fragment in the test lanes indicated presence of MTBC in the sample provided controls were valid.

\section{Patient follow-up}

To determine survival status and confirm diagnosis of $\mathrm{TB}$, follow-up at 2 months (window 8 to 16 weeks) was done for PCR-positive/culture negative as well as PCRnegative/culture negative study participants and the outcomes of both categories compared. ZN-sputum microscopy was performed during the follow-up visits. Additionally, medical records and additional test-results were also reviewed. Information was obtained by telephone interviews for participants who were unable to return for follow-up visits. Patients were classified as having PTB based on any of the following: MTBC isolated in at least one culture; positive $\mathrm{ZN}$ sputum smear; granulomas on histopathology; and clinical response to TB treatment in absence of a non-TB alternative diagnosis.

\section{Quality control}

Cross contamination of cultures was minimized through use of sterile disposable aerosol resistant tips. For each sample, separate tubes with decontamination/phosphate buffers were used to avoid cross-transfer of specimens. Samples with only phosphate buffer were always included in the batch being processed and these remained negative upon culture. For molecular assays, separate rooms were used for sample preparation, reaction mixes, DNA amplification and detection. After use, UV hoods were decontaminated by turning on UV light. Negative controls were included in each PCR batch to detect cross-contamination during premixes. To determine the effect of PCR inhibitors, reactions were spiked with $500 \mathrm{ng}$ of MTB chromosomal DNA from the reference strain $\mathrm{H}_{37} \mathrm{Rv}$ (ATCC 27294) and ran in parallel; amplification of the IS6110 fragment implied absence of or minimal PCR inhibition. All laboratory personnel were blinded to the clinical and culture data.

\section{Data analysis}

The data were analyzed with STATA version 10.0 (StataCorp LP, College Station, TX, USA). The sensitivity, specificity, positive and negative predictive values as well as diagnostic likelihood ratios for in-house PCR assay were calculated using LJ culture as the base line test. To compare clinical outcomes (TB diagnosis and mortality) at 2 months of follow-up between PCR-positive/culture negative and PCR-negative/culture negative participants, a Z-test was used to test for differences in proportions. A $p$ value of $<0.05$ was considered statistically significant.

\section{Ethical considerations}

The study was approved by the Makerere University Faculty of Medicine Research and Ethics Committee. Written informed consent was obtained from all the patients who participated in this study.

\section{Results}

Two hundred and five smear-negative PTB suspects were recruited, with a mean age of 34.7 years $( \pm 10.4$ standard deviation) and an equal gender distribution. There were few smokers and most patients were HIVinfected $(85.9 \%, 176 / 205)$, of whom $72.2 \%$ (127/176) had advanced immunosuppression (CD4+ cell count of $\leq 200$ cells $/ \mu \mathrm{L})$. Furthermore, many patients had abnormal chest findings $(76.1 \%, 156 / 205)$. Although many patients reported fever, only $41 \% \quad(84 / 205)$ had a body temperature of $\geq 37.5^{\circ} \mathrm{C}$ at enrolment (Table 1 ).

Of the 205 cultured samples, 72 (35.1\%) grew mycobacterial colonies on LJ media. Since LJ culture method has been found non-conducive for growth of nontuberculous mycobacteria in our setting [21,22] all the LJ culture-positive samples were regarded as MTBC. Furthermore, 128 (62.4\%) samples had no visible growth while five (2.4\%) cultures were contaminated (Figure 1).

Of the 205 sputum samples analyzed by in-house PCR, $19(9.3 \%, 19 / 205)$ results were not available leaving 186 (90.7\%, 186/205) PCR results for analysis. Of the 186, $128(68.8 \%, 128 / 186)$ were confirmed as MTBC while 
Table 1 Baseline characteristics of smear-negative PTB suspects $(n=205)$

\begin{tabular}{lcc}
\hline Characteristics & Frequency & Percentage \\
\hline Socio-demographics & & \\
Females & 105 & 51.2 \\
Never smoked & 140 & 68.2 \\
Smoked & 65 & 31.8
\end{tabular}

Clinical parameters as reported by patients

\begin{tabular}{|c|c|c|}
\hline Cough (>2 weeks) & 205 & 100 \\
\hline Fever and/or night sweats & 193 & 94.1 \\
\hline Weight loss & 191 & 93.2 \\
\hline Wheezing & 42 & 20.5 \\
\hline Difficulty in breathing & 130 & 63.4 \\
\hline Blood in sputum & 57 & 30.1 \\
\hline Antibiotic exposure in previous 2 weeks & 84 & 41.0 \\
\hline \multicolumn{3}{|l|}{ Clinical examination (physical) } \\
\hline \multicolumn{3}{|l|}{ Body temperature $\left({ }^{\circ} \mathrm{C}\right)^{*}$} \\
\hline$<37.5$ & 113 & 57.4 \\
\hline$\geq 37.5$ & 84 & 42.6 \\
\hline$\leq 20$ & 45 & 23.6 \\
\hline$>20$ & 146 & 76.4 \\
\hline \multicolumn{3}{|l|}{$\begin{array}{l}\text { Oxygen saturation (\% measured by } \\
\text { a pulseoximeter)* }\end{array}$} \\
\hline$\leq 90$ & 47 & 23.1 \\
\hline$>90$ & 156 & 76.9 \\
\hline \multicolumn{3}{|l|}{$\begin{array}{l}\text { Pulse rate, beats/min (measured by } \\
\text { a pulseoximeter) }\end{array}$} \\
\hline Median rate (percentile range) & 106 (88 to119) & \\
\hline \multicolumn{3}{|l|}{ Lung examination } \\
\hline Normal (clear chest) & 49 & 23.9 \\
\hline $\begin{array}{l}\text { Abnormal (Rhonchi, crepitation, bronchial } \\
\text { breathing, absent breath sounds) }\end{array}$ & 156 & 76.1 \\
\hline \multicolumn{3}{|l|}{ HIV status } \\
\hline Positive & 176 & 85.9 \\
\hline Negative & 29 & 14.1 \\
\hline \multicolumn{3}{|l|}{ CD4 Cell Count* (cell/ml) } \\
\hline$\leq 200$ & 127 & 76 \\
\hline$>200$ & 40 & 24 \\
\hline
\end{tabular}

*Some measurements missing.

five $(5 / 186)$ had the corresponding $\mathrm{LJ}$ culture results contaminated hence excluded (Figure 1).

\section{Performance of the in-house PCR in diagnosing} smear-negative PTB

Five PCR samples had culture results contaminated and were excluded from the analysis leaving 181corresponding
Table 2 Performance indices for In-house PCR using LJ Culture as the base line test

\begin{tabular}{lccr}
\hline & Culture Positive & Culture Negative & Total \\
\hline$P C R$ Positive & 48 & 75 & 123 \\
$P C R$ Negative & 16 & 42 & 58 \\
Total & 64 & 117 & 181 \\
\hline
\end{tabular}

PCR and LJ culture results (Figure 1 and Table 2). The sensitivity and specificity of in-house PCR in diagnosing smear-negative PTB was $75 \%$ (95\% CI 62.6-85.0) and $35.9 \%$ (95\% CI 27.2-45.3), respectively. The positive and the negative predictive values were $39 \%$ (95\% CI 30.448.2 ) and $72.4 \%$ (95\% CI 59.1-83.3), respectively. The positive and negative likelihood ratios were $1.17,95 \% \mathrm{CI}$ (0.96-1.42) and 0.7, 95\% CI (0.43-1.14) respectively. Details of these performance indices are shown in Tables 2 and 3.

\section{Clinical outcomes}

One hundred and seventeen culture-negative suspects (75 PCR-positive and 42 PCR-negative) were enrolled for the 2 months follow-up visit. Of the 75 PCR-positive ones, 45 (60\%) were still alive of whom 29 (64.4\%, 29/ 45) returned for the follow-up visit; 15 (20\%) suspects died while another $15(20 \%)$ were lost to follow-up (Figure 2). Of the 42 PCR-negative suspects, 22 (52.4\%) were still alive of whom $16(72.7 \%, 16 / 22)$ returned for follow-up (Figure 2); 11 (26.2\%, 11/42) suspects died while nine $(21.4 \%, 9 / 42)$ were lost to follow-up.

Overall, more PCR-positive suspects were diagnosed with TB during follow-up but the difference was not statistically significant $(27.6 \%, 8 / 29$ vs. $25 \%, 4 / 16$, $p=0.9239$ ). On the other hand, mortality was higher for PCR-negative suspects but the difference was also not statistically significant $(26.2 \%$ vs. $20 \% p=0.7094)$.

\section{Discussion}

In this study, in-house PCR correlated poorly with LJ culture for diagnosis of smear-negative PTB. Although reported previously in other settings [25,26], this is among the few studies evaluating the performance of inhouse PCR on smear-negative PTB suspects in Uganda, a low income country with high rates of HIV/TB co-infection. The sensitivity for the in-house PCR in the

Table 3 More performance indices for In-house PCR

\begin{tabular}{lcc}
\hline Performance Indices & Index value & $\mathbf{9 5 \% ~ C l}$ \\
\hline Sensitivity & $75 \%$ & $62.6-85.0$ \\
Specificity & $35.9 \%$ & $27.2-45.3$ \\
Positive Predictive Value & $39 \%$ & $30.4-48.2$ \\
Negative Predictive Value & $72.4 \%$ & $59.1-83.3$ \\
Diagnostic Likelihood ratio (Positive) & 1.17 & $0.96-1.42$ \\
Diagnostic Likelihood ratio (Negative) & 0.70 & $0.43-1.14$ \\
\hline
\end{tabular}




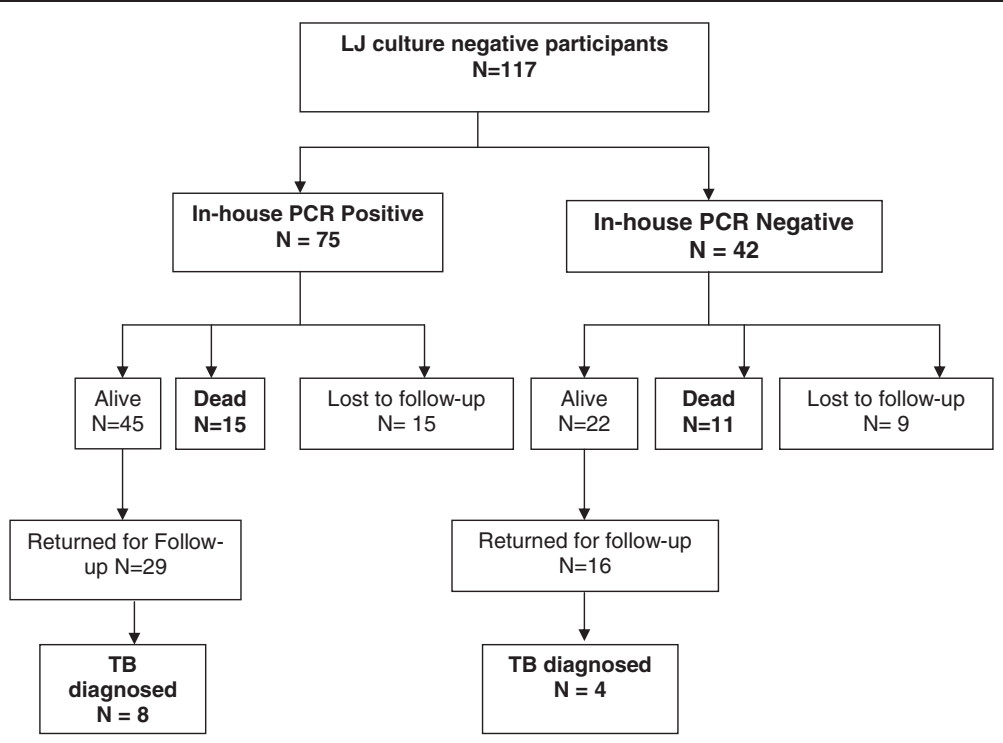

Figure 2 Clinical outcomes for LJ-culture negative patients comparing PCR-positive and PCR-negative groups at 2 months follow-up.

current study was higher than that reported in an earlier African study on ZN-negative sputum samples (i.e., 75\% vs. 40\%) [26]. Although we endeavored to control for PCR inhibitors, the sensitivity of the DNA polymerase can be affected by the paucibacillary nature of specimens [27], which could also have affected the PCR assay sensitivity in our study.

Although the performance indices in this study were estimated with LJ culture which is not the gold standard for MTBC identification, virtually all LJ-positive cultures in this setting are MTBC and speciation tests to confirm MTB are deemed unnecessary since colonies are presumptively MTBC [22]. LJ culture also is widely used as a gold standard for TB diagnosis in RLS [20].

Since our concern was mostly TB-diagnosis (i.e. patient-care) of which LJ is the gold standard for MTBC culture, we thus did not speciate cultures but confirmed the presumptive MTBC as mycobacteria through $16 \mathrm{~S}$ rRNA PCR.

Specificity for the in-house PCR in the current study was also low (35.9\%). Although a couple of PCR studies have achieved high specificity with smear-negative PTB, they mostly worked with commercial tests $[28,29]$ that are expensive for many in RLS. Otherwise, most studies with in-house PCR on smear-negative PTB have revealed substantial variability in specificity $[28,30]$.

It is still possible that the many false positives in the current study could have resulted from the low sensitivity of LJ culture [22,31]. Indeed, the culture-positive/ PCR-negative isolates could have been NTM, which are known to cause severe disease in immunocompromised HIV-positive patients with low CD4+ counts. Moreover, majority of the subjects in this study were HIV-infected with low CD4+ cell counts. We hope future studies will consider these omissions (i.e. speciating NTM among AFB smear-negative PTB suspects).

Furthermore, while the Flores et al. 2005, metaanalysis for in-house PCR accuracy [28] found the IS6110 amplification target highly accurate, this was not shown in the current study, meaning that IS6110 alone may not be adequate for increased diagnostic yield. The diagnostic likelihood ratio (DLR) for a positive in-house PCR was 1.17 [95\% CI (0.96-1.42)] implying that a positive in-house PCR test may not indicate presence of MTBC. Likewise, the negative DLR was 0.7 [95\% CI (0.43-1.14)] implying that a negative in-house PCR test is not indicative of absence of MTBC. Therefore, with in-house PCR in this setting, a clinician will need additional diagnostic methods to confirm PTB in smearnegative suspects.

There was no significant difference in mortality and diagnosis of TB at follow-up between PCR-positive/culture negative and PCR-negative/culture negative PTB suspects, although mortality was higher for PCR-negative suspects. However, this could be due to other factors that were not addressed, for instance co-morbidities.

\section{Limitations}

Due to limited funding, we did not use biochemical tests or DNA sequencing which methods are considered gold standards for MTBC identification; probably these would have provided higher accuracy estimates for the inhouse PCR. Species-confirmation of the LJ-positive cultures was not done in light of recent findings in parallel studies in this setting, in which AFB growth on LJ medium is virtually MTBC $[21,22]$. 
Few participants returned for the follow-up visits and we were unable to establish the possible cause of death in the participants who died. Although predictive values are reported, these cannot be accurately interpreted in this pooled population. Lastly, this study does not represent the general use of in-house PCR in a real world setting, since PCR methods vary widely with setting and the data herein may not be generalizable.

\section{Conclusions}

In-house PCR is inefficient for diagnosis of smear-negative PTB. Its diagnostic accuracy is low and it may not be used as an alternative for LJ culture in this setting.

\section{Abbreviations}

AFB: Acid fast bacilli; BSL-3: Biosafety level 3; DMSO: Dimethyl sulfoxide; dNTPs: Deoxyribonucleotide triphosphates; EDTA: Ethylenediaminetetraacetic acid; ELISA: Enzyme linked immunosorbent assays; HIV: Human immunodeficiency virus; LJ: Lowenstein-Jensen media; MTB: Mycobacterium tuberculosis; MTBC: Mycobacterium tuberculosis complex; NAAT: Nucleic acid amplification tests; NALC: N-Acetyl L-cysteine; NPV: Negative predictive value; NTRL: National tuberculosis reference laboratory; NTM: Non tuberculous mycobacteria; PCR: Polymerase chain reaction; PPV: Positive predictive value; PTB: Pulmonary tuberculosis; RLS: Resource limited settings; TB: Tuberculosis; TBE: Tris-Borate EDTA; UV: Ultraviolet light; WHO: World health organization; ZN: Ziehl-Neelson.

\section{Competing interests}

The authors declare that they have no competing interests.

\section{Authors' contributions}

LN, PO, MLJ, HMK, LH conceived and designed the study. LN and FAK performed the molecular assays. LN, JBS, WW, AK, MLJ and HMK analyzed the data. LN, DPK and PO wrote the manuscript. All authors read and approved the manuscript.

\section{Acknowledgements}

The authors thank the Fogarty International Clinical Research Scholars and Fellows Program (FIRCS-F) and Makerere University Infectious Diseases Institute (IDI) for the scientific and financial support; the staff at Mulago Hospital, Ward 3BEM; the laboratory technicians; the MIND- IHOP study team; the Makerere University Department of Medical Microbiology (Molecular biology laboratory) and the NTRL for laboratory support; and the study participants. The authors also thank Professor Walter Schlech of Dalhousie University, Canada, for proof reading the manuscript.

\section{Author details}

${ }^{1}$ Infectious Diseases Institute, Makerere University College of Health Sciences, Mulago Hospital Complex, Kampala, Uganda. ${ }^{2}$ Department of Medicine, School of Medicine, Makerere University College of Health Sciences, Kampala, Uganda. ${ }^{3}$ Department of Medical Microbiology, School of Biomedical Sciences, Makerere University College of Health Sciences, Kampala, Uganda. ${ }^{4}$ HIV/AIDS Division and Division of Pulmonary and Critical Care Medicine, San Francisco General Hospital, University of California-San Francisco, San Francisco, CA, USA.

Received: 12 December 2011 Accepted: 31 August 2012

Published: 5 September 2012

\section{References}

1. Cole ST: Comparative and functional genomics of the Mycobacterium tuberculosis complex. Microbiology 2002, 148(Pt 10):2919-2928.

2. Gagneux S, Burgos MV, DeRiemer K, Enciso A, Muñoz S, Hopewell PC, Small PM, Pym AS: Impact of Bacterial Genetics on the Transmission of Isoniazid-Resistant Mycobacterium tuberculosis. PLoS Pathog 2006 2(6):e61.
3. WHO: Global tuberculosis control: epidemiology, strategy, financing WHO report. 2009, Available from: http://www.ghdonline.org/uploads/ WHO_TB_report_without_annexes_2009.pdf.

4. USAID: Uganda Tuberculosis Country Profile. [www.usaid.gov/our_work] global_health/id/tuberculosis/.../uganda.pdf]

5. The deadly synergy of HIV and tuberculosis. Lancet Infect Dis 2010, 10 (7):441. doi:10.1016/S1473-3099(10)70124-9.

6. El-Sadr WM, Tsiouris SJ: HIV-associated tuberculosis: diagnostic and treatment challenges. Semin Respir Crit Care Med 2008, 29(5):525-531.

7. Tsiouris SJ, Gandhi NR, El-Sadr WM, Friedland G: Tuberculosis and HIVneeded: a new paradigm for the control and management of linked epidemics. MedGenMed 2007, 9(3):62.

8. Nahid P, Pai M, Hopewell PC: Advances in the diagnosis and treatment of tuberculosis. Proc Am Thorac Soc 2006, 3(1):103-110.

9. Foulds J, O'Brien R: New tools for the diagnosis of tuberculosis: the perspective of developing countries. Int J Tuberc Lung Dis 1998, 2(10):778-783.

10. Perkins MD: New diagnostic tools for tuberculosis. Int J Tuberc Lung Dis 2000, 4(12 Suppl 2):S182-188.

11. Reid MJA, Shah NS: Approaches to tuberculosis screening and diagnosis in people with HIV in resource-limited settings. Lancet Infect Dis 2009, 9(3):173-184.

12. Shen G-H, Chiou C-S, Hu S-T, Wu K-M, Chen J-H: Rapid Identification of the Mycobacterium tuberculosis Complex by Combining the ESAT-6/CFP-10 Immunochromatographic Assay and Smear Morphology. J Clin Microbiol 2011, 49(3):902-907.

13. Desmond EP, Loretz K: Use of the Gen-Probe amplified mycobacterium tuberculosis direct test for early detection of Mycobacterium tuberculosis in BACTEC 12B medium. J Clin Microbiol 2001, 39(5):1993-1995.

14. Ryang DW, Ryang DH, Shin MG, Shin JH, Kee SJ, Suh SP: Alternative use of polymerase chain reaction instead of rho-nitro-alpha-acetylamino-betahydroxypropiophenone test for the early detection of Mycobacterium tuberculosis in BACTEC 12B cultures. APMIS 1996, 104(6):444-450.

15. Evans CA: GeneXpert-a game-changer for tuberculosis control? PLOS Med 2011, 8(7):e1001064. doi:10.1371/journal.pmed.1001064.

16. Muhumuza J, Asiimwe BB, Kayes S, Mugyenyi P, Whalen C, Mugerwa RD, Boom $\mathrm{H}$, Eisenach KD, Joloba ML: Introduction of an in-house PCR for routine identification of $M$. tuberculosis in a low-income country. Int J Tuberc Lung Dis 2006, 10:1262-1267.

17. Harries A, Maher D, WHO: TB/HIV, a clinical manual. 1996, http://www. uphs.upenn.edu/bugdrug/antibiotic_manual/TB-HIVclinicalmanual.pdf.

18. The Ministry of Health, Uganda: Uganda National Policy Guidelines for HIV Counselling and Testing. www.who.int/hiv/pub/guidelines/uganda_art.pdf.

19. Kent L, McHugh T, Billington O, Dale J, Gillespie S: Demonstration of homology between IS6110 of Mycobacterium tuberculosis and DNAs of other Mycobacterium spp.? [published erratum appears in J Clin Microbiol 1995 Nov;33(11):3082]. J Clin Microbiol 1995, 33(9):2290-2293.

20. Zhu C, Cui Z, Zheng R, Yang H, Jin R, Qin L, Liu Z, Wang J, Hu Z: A multicenter study to evaluate the performance of phage amplified biologically assay for detecting TB in sputum in the pulmonary TB patients. PLoS One 2011, 6(9):e24435.

21. Lukoye D, Cobelens FG, Ezati N, Kirimunda S, Adatu FE, Lule JK, Nuwaha F, Joloba ML: Rates of anti-tuberculosis drug resistance in Kampala-Uganda are low and not associated with HIV infection. PLOS One 2011 6(1):e16130.

22. Worodria W, Anderson J, Cattamanchi A, Davis JL, den Boon S, Andama A, Yoo SD, Joloba M, Huang L, Kato-Maeda M: The role of speciation in positive lowenstein-jensen culture isolates from a high tuberculosis burden country. PLoS One 2011, 6(11):e27017.

23. Cave MD, Eisenach KD, McDermott PF, Bates JH, Crawford JT: IS6110: conservation of sequence in the Mycobacterium tuberculosis complex and its utilization in DNA fingerprinting. Mol Cell Probes 1991, 5(1):73-80.

24. Hellyer TJ, DesJardin LE, Assaf MK, Bates JH, Cave MD, Eisenach KD: Specificity of IS6110-based amplification assays for Mycobacterium tuberculosis complex. J Clin Microbiol 1996, 34(11):2843-2846.

25. Sarmiento OL, Weigle KA, Alexander J, Weber DJ, Miller WC: Assessment by meta-analysis of PCR for diagnosis of smear-negative pulmonary tuberculosis. J Clin Microbiol 2003, 41(7):3233-3240.

26. Kambashi B, Mbulo G, McNerney R, Tembwe R, Kambashi A, Tihon V Godfrey-Faussett P: Utility of nucleic acid amplification techniques for the 
diagnosis of pulmonary tuberculosis in sub-Saharan Africa. Int J Tuberc Lung Dis 2001, 5(4):364-369.

27. Amicosante M, Richeldi L, Trenti G, Paone G, Campa M, Bisetti A, Saltini C: Inactivation of polymerase inhibitors for Mycobacterium tuberculosis DNA amplification in sputum by using capture resin. J Clin Microbiol 1995, 33(3):629-630

28. Flores LL, Pai M, Colford JM Jr, Riley LW: In-house nucleic acid amplification tests for the detection of Mycobacterium tuberculosis in sputum specimens: meta-analysis and meta-regression. BMC Microbiol 2005, 5:55.

29. Brodie D, Schluger NW: The diagnosis of tuberculosis. Clin Chest Med 2005, 26(2):247-271. vi.

30. Rattan A: PCR for diagnosis of tuberculosis: where are we now? Ind J Tub 2000, 47:79-82.

31. Negi SS, Khan SF, Gupta S, Pasha ST, Khare S, Lal S: Comparison of the conventional diagnostic modalities, bactec culture and polymerase chain reaction test for diagnosis of tuberculosis. Indian J Med Microbiol 2005, 23(1):29-33.

doi:10.1186/1756-0500-5-487

Cite this article as: Nakiyingi et al:: Evaluation of in-house PCR for

diagnosis of smear-negative pulmonary tuberculosis in Kampala, Uganda. BMC Research Notes 2012 5:487.

\section{Submit your next manuscript to BioMed Central and take full advantage of:}

- Convenient online submission

- Thorough peer review

- No space constraints or color figure charges

- Immediate publication on acceptance

- Inclusion in PubMed, CAS, Scopus and Google Scholar

- Research which is freely available for redistribution 